\title{
Review \\ Molecular and Clinical Features of EGFR-TKI-Associated Lung Injury
}

\author{
Tohru Ohmori ${ }^{1}$, Toshimitsu Yamaoka ${ }^{1,2, * \mathbb{C}}$, Koichi Ando ${ }^{1}$, Sojiro Kusumoto ${ }^{1}$, Yasunari Kishino ${ }^{1}$, \\ Ryou Manabe ${ }^{1}$ and Hironori Sagara ${ }^{1}$ (D) \\ 1 Department of Medicine, Division of Respiratory Medicine and Allergology, Showa University School \\ of Medicine, 1-5-8 Hatanodai, Shinagawa-ku, Tokyo 142-8666, Japan; ohmorit@med.showa-u.ac.jp (T.O.); \\ koichi-a@med.showa-u.ac.jp (K.A.); k-sojiro@med.showa-u.ac.jp (S.K.); ookiyookiy@med.showa-u.ac.jp (Y.K.); \\ r.manabe@med.showa-u.ac.jp (R.M.); sagarah@med.showa-u.ac.jp (H.S.) \\ 2 Advanced Cancer Translational Research Institute, Showa University, 1-5-8 Hatanodai, Shinagawa-ku, \\ Tokyo 142-8555, Japan \\ * Correspondence: yamaoka.t@med.showa-u.ac.jp; Tel.: +81-3-3784-8146
}

Citation: Ohmori, T.; Yamaoka, T.; Ando, K.; Kusumoto, S.; Kishino, Y.; Manabe, R.; Sagara, H. Molecular and Clinical Features of EGFR-TKIAssociated Lung Injury. Int. J. Mol. Sci. 2021, 22, 792. https://doi.org/ 10.3390/ijms22020792

Received: 23 December 2020 Accepted: 12 January 2021 Published: 14 January 2021

Publisher's Note: MDPI stays neutral with regard to jurisdictional clai$\mathrm{ms}$ in published maps and institutional affiliations.

Copyright: (C) 2021 by the authors. Licensee MDPI, Basel, Switzerland. This article is an open access article distributed under the terms and conditions of the Creative Commons Attribution (CC BY) license (https:// creativecommons.org/licenses/by/ $4.0 /)$.

\begin{abstract}
The tyrosine kinase activity of epidermal growth factor receptors (EGFRs) plays critical roles in cell proliferation, regeneration, tumorigenesis, and anticancer resistance. Non-small-cell lung cancer patients who responded to EGFR-tyrosine kinase inhibitors (EGFR-TKIs) and obtained survival benefits had somatic EGFR mutations. EGFR-TKI-related adverse events (AEs) are usually tolerable and manageable, although serious AEs, including lung injury (specifically, interstitial lung disease (ILD), causing $58 \%$ of EGFR-TKI treatment-related deaths), occur infrequently. The etiopathogenesis of EGFR-TKI-induced ILD remains unknown. Risk factors, such as tobacco exposure, pre-existing lung fibrosis, chronic obstructive pulmonary disease, and poor performance status, indicate that lung inflammatory circumstances may worsen with EGFR-TKI treatment because of impaired epithelial healing of lung injuries. There is limited evidence from preclinical and clinical studies of the mechanisms underlying EGFR-TKI-induced ILD in the available literature. Herein, we evaluated the relationship between EGFR-TKIs and AEs, especially ILD. Recent reports on mechanisms inducing lung injury or resistance in cytokine-rich circumstances were reviewed. We discussed the relevance of cytotoxic agents or immunotherapeutic agents in combination with EGFR-TKIs as a potential mechanism of EGFR-TKI-related lung injury and reviewed recent developments in diagnostics and therapeutics that facilitate recovery from lung injury or overcoming resistance to anti-EGFR treatment.
\end{abstract}

Keywords: EGFR-TKIs; lung injury; inflammation; TNF

\section{Introduction}

Lung cancer is the leading cause of death worldwide [1]. Immunotherapy and targeted therapy, in selected populations, has achieved major improvements in the prognosis of patients with advanced non-small cell lung cancer (NSCLC) [2]. Epidermal growth factor receptor (EGFR) mutations, which are detected in up to $50 \%$ of patients with lung adenocarcinoma, are recognized as the major actionable target in Asians [3]. Three generations of EGFR-tyrosine kinase inhibitors (TKIs) have been developed and approved for the treatment of advanced NSCLC in patients carrying EGFR-activating mutations. These EGFR-TKIs, which include first-generation (gefitinib and erlotinib), second-generation (afatinib and dacomitinib), and third-generation (osimertinib) agents, have induced improved outcomes, including efficacy and safety, overall when compared with standard chemotherapy [4].

With EGFR-TKI treatment, NSCLC patients who have EGFR-activating mutations can achieve longer progression-free survival (PFS) and a higher quality of life [5-7]. The EGFR-TKIs are generally well tolerated because of a favorable toxicity profile compared 
to chemotherapeutic agents. EGFR plays an essential role in epithelial maintenance and, therefore, EGFR-TKIs might impair epithelial cell growth and migration and alter cytokine expression, leading to the recruitment of inflammatory cells and consequent tissue injury. For example, diarrhea, acneiform skin rash, and paronychia are the commonest side effects of EGFR-TKIs. Mucositis, stomatitis, corneal erosion, and epistaxis are less common, but are clinically important. These side effects are associated with the effect of wild-type-EGFR inhibition. Hepatic and pulmonary toxicity has been reported to be an EGFR-TKI-associated fatal event $[8,9]$. Severe hepatic dysfunction can be managed by switching to another EGFRTKI, whereas lung injury (also known as interstitial lung disease (ILD)) often leads to the discontinuation of EGFR-TKI treatment in the affected patients [10]. ILD is a rare but serious complication of EGFR-TKI because one-third of the patients with EGFR-TKI-associated lung injury die, even after receiving intensive supportive care, including supplemental oxygen, empirical antibiotics, systemic corticosteroids, and mechanical ventilation. Therefore, lung injury is the most life-threatening adverse event (AE) related to EGFR-TKI treatment. However, the mechanisms mediating the association between EGFR-TKI treatment and lung injury is not well known. The NSCLC patients with EGFR-TKI-induced lung injury had characteristic clinical profiles of risk factors, including smoking history, male sex, and pre-existing lung fibrosis. On the basis of these patient profiles, it is possible to speculate that lung injury would be worsened by EGFR-TKI treatment in patients with chronic inflammation.

This review focused on the relationship between EGFR-TKIs and AEs, especially lung injury. We reviewed recent reports concerning the mechanisms that induce lung injury or resistance in cytokine-rich circumstances. We discussed the relevance of cytotoxic agents or immunotherapeutic agents in combination with EGFR-TKIs as a potential pathogenic mechanism of EGFR-TKI-related lung injury. Furthermore, we reviewed recent developments in diagnostics and therapeutics that may help to prevent lung injury or to overcome resistance to anti-EGFR treatment.

\section{Development of EGFR-TKIs and Their AEs}

\subsection{Development of EGFR-TKIs in Clinical Studies}

Targeted drug treatment directed at oncogenes has garnered dramatic clinical benefits and has ushered in an era of "targeted therapy". Similar efforts are underway for cancers with the identification of several potentially promising targetable molecular drivers. Since the discovery of EGFR-activating mutations in NSCLC patients and the elucidation of their response to EGFR-specific TKIs, additional molecular-specific cohorts of NSCLC have been discovered, with the rapid development of targeted drugs specific to each respective abnormality [11]. Treatment with an EGFR-TKI is the current standard of care for patients with locally advanced or metastatic NSCLC who have active mutations.

Currently, several EGFR-TKIs are available for NSCLC patients with EGFR-activating mutations. First-generation EGFR-TKIs (gefitinib and erlotinib) exhibit excellent efficacy. Second-generation covalent inhibitors of EGFR (afatinib and dacomitinib) demonstrate increased cellular inhibitory potency against the driver variants in EGFR [12]. To counter T790M-dependent resistance, a third-generation covalent EGFR-TKI (osimertinib) has been developed with a high potency toward T790M-containing mutants and selectivity over wild-type EGFR [13]. Sections 2.1.1-2.1.3 present the background of the development and the results of clinical trials of each generation of EGFR-TKIs.

\subsubsection{First-Generation EGFR-TKIs}

The Iressa Pan-Asia Study evaluated gefitinib, compared with carboplatin-paclitaxel, as an initial treatment for NSCLC in East Asian non-smokers or former light smokers with pulmonary adenocarcinoma and found that gefitinib treatment prolonged progression-free survival (PFS), increased the objective response rate, reduced toxic effects, and improved the quality of life [7]. Subsequent analysis revealed gefitinib sensitivity in the patient subgroups with EGFR mutation-positive NSCLC. In the North East Japan (NEJ) 002 and 
West Japan Thoracic Oncology Group 3405 trials of gefitinib versus chemotherapy in patients with EGFR mutation-positive NSCLC, gefitinib extended the PFS (median PFS, 10.8 months for gefitinib vs. 5.4 months for chemotherapy; hazard ratio (HR), $0.30 ; p<0.001$ and median PFS, 9.2 months for gefitinib vs. 6.3 months for chemotherapy; HR, 0.48 ; $p<0.0001$, respectively) [14,15].

\subsubsection{Second-Generation EGFR-TKIs}

A randomized phase IIb trial of gefitinib versus afatinib in patients with NSCLC showed that afatinib extended the PFS (median PFS, 11.0 months for afatinib vs. 10.9 months for gefitinib; HR, 0.73; $p=0.017$ ), but failed to extend the overall survival (OS; median OS, 27.9 months for afatinib vs. 24.5 months for gefitinib; HR, 0.86; $p=0.025$ ) [16,17]. A randomized phase III trial of gefitinib versus dacomitinib in NSCLC patients showed that dacomitinib extended the PFS and OS (median PFS 14.7 months for dacomitinib vs. 9.2 months for gefitinib; HR, $0.59 ; p<0.0001$ and median OS, 34.1 months for dacomitinib vs. 26.8 months for gefitinib; HR, 0.76; $p=0.044$, respectively) [18,19].

\subsubsection{Third-Generation EGFR-TKI}

A randomized phase III trial of osimertinib versus gefitinib or erlotinib in NSCLC patients (FLAURA study) revealed that osimertinib extended the PFS (median PFS, 18.9 months for osimertinib vs. 10.2 months for gefitinib or erlotinib; HR, $0.46 ; p<0.001$ and median OS 38.6 months for osimertinib vs. 31.8 months for gefitinib or erlotinib; HR, $0.80 ; p=0.046$, respectively) [20,21]. As compared to first-generation EGFR-TKIs, osimertinib has shown superior efficacy in the central nervous system. Based on these results, osimertinib has been used as first-line therapy in NSCLC patients with EGFR-activating mutations [20]. Given its effectiveness and tolerability, osimertinib is a mainstay in the treatment of EGFR mutation-positive NSCLC.

\subsection{Adverse Events of EGFR-TKIs and Their Management}

Molecular targeted drugs such as EGFR-TKIs were initially considered safe anti-cancer drugs with only minor AEs; however, it is known that targeted molecular therapeutic agents can cause serious AEs, including fatal illness. All generations of EGFR-TKIs have similar side-effect profiles, although the frequency and severity of AEs vary by the respective drugs. Rash, paronychia, and diarrhea were the most common AEs reported with first- and second-generation EGFR-TKIs [22]. These drugs inhibit not only active mutant EGFR but also wild-type EGFR, and normal tissues that express EGFR are impaired by the "target effect". Osimertinib, with selectivity to active mutant EGFR, has been developed and has been associated with relatively mild AEs [20]. Infrequently, serious AEs, including drug-induced lung injury (mainly ILD), occur with all generations of EGFR-TKIs. In this subsection, we describe the AEs of EGFR-TKIs and their management.

\subsubsection{Rash, Paronychia, and Stomatitis}

Skin disorders are the commonest EGFR-TKI-associated AE and include rashes, such as acne, dry skin, and paronychia. Rash (all grades) associated with EGFR-TKI use is seen in $61-78 \%, 78-92.4 \%, 88 \%$, and $58 \%$ of patients treated with gefitinib, erlotinib, afatinib, and osimertinib, respectively (Table 1) $[14,16,20,23]$. Severe (grade 3 or 4 ) rash is seen in $1-7 \%$, $7-18.1 \%, 1 \%$, and $1 \%$ of patients treated with gefitinib, erlotinib, afatinib, and osimertinib, respectively (Table 1) $[14,16,20,23]$. Paronychia (all grades) associated with EGFR-TKIs use is seen in $17-33 \%, 33 \%, 56 \%$, and $35 \%$ of patients treated with gefitinib, erlotinib, afatinib, and osimertinib, respectively $[14,16,20,23]$. Severe (grade 3 or 4 ) paronychia is seen in $1 \%, 1-4.3 \%, 2 \%$, and $<1 \%$ of patients treated with gefitinib, erlotinib, afatinib, and osimertinib, respectively $[14,16,20,23]$. Stomatitis (all grades) associated with EGFR-TKI use is seen in $20-24 \%, 20 \%, 64 \%$, and $29 \%$ of patients treated with gefitinib, erlotinib, afatinib, and osimertinib, respectively $[14,16,20,24]$. Severe (grade 3 or 4 ) stomatitis is seen in $<1 \%,<1 \%, 4 \%$, and $<2 \%$ of patients treated with gefitinib, erlotinib, afatinib, and 
osimertinib, respectively $[14,16,20,24]$. The management of skin disorders involves both preemptive interventions and treatment after the symptoms occur. The basic preemptive intervention is moisturizing. The moisture content in the skin would have decreased since the initiation of EGFR-TKI treatment, and moisturizers can alleviate this decrease [23]. The use of products that can dry the skin, such as soaps and alcohol-based or perfumed products, should be avoided, shower time should be limited, and the use of lukewarm rather than hot water should be recommended [25]. If signs or symptoms of a rash appear, active application of corticosteroids at an early stage is required. For acne that is refractory to corticosteroid application, an orally administered tetracycline regimen is recommended. For paronychia, preemptive interventions include keeping nails trimmed and avoiding extreme temperatures, friction, or other injuries; taping of fingertips relieves pain. Stomatitis requires preventive oral care and ascertaining the compatibility of dentures. When stomatitis worsens, topical corticosteroids and azulene and Chinese herbal medicine gargles (Ban Xia Xie Xin Tang) are used together.

Table 1. Incidence of class-specific adverse events associated with epidermal growth factor receptor (EGFR)-tyrosine kinase inhibitors (TKIs) for treatment of non-small cell lung cancer (NSCLC).

\begin{tabular}{|c|c|c|c|c|c|c|c|c|c|c|}
\hline \multirow[b]{2}{*}{ Trial } & \multirow[b]{2}{*}{ Drugs } & \multirow[b]{2}{*}{$\mathbf{n}$} & \multicolumn{2}{|c|}{ Rash } & \multicolumn{2}{|c|}{ Diarrhea } & \multicolumn{2}{|c|}{ AST/ALT Elevation } & \multicolumn{2}{|c|}{ ILD } \\
\hline & & & ALL (\%) & $\geq \mathrm{G} 3(\%)$ & ALL (\%) & $\geq \mathrm{G} 3(\%)$ & ALL (\%) & $\geq \mathrm{G} 3(\%)$ & ALL (\%) & $\geq \mathrm{G} 3(\%)$ \\
\hline \multirow[t]{2}{*}{ NEJ002 } & Gefitinib & 144 & 71.0 & 5.3 & 34.2 & 0.9 & 55.2 & 26.3 & 5.3 & 2.6 \\
\hline & Carbo/Pacli ${ }^{1}$ & 144 & 19.2 & 2.7 & 6.1 & 0 & 32.4 & 0.9 & 0 & 0 \\
\hline \multirow[t]{2}{*}{$\begin{array}{l}\text { WJOG } \\
5108 \mathrm{~L}\end{array}$} & Gefitinib & 277 & 74.7 & 2.2 & 42.6 & 2.2 & $42.2 / 50.9$ & $6.1 / 13.0$ & 4.3 & 0.4 \\
\hline & Erlotinib & 276 & 92.4 & 18.1 & 51.1 & 3.3 & $34.9 / 38.2$ & $2.2 / 3.3$ & 4.0 & 1.4 \\
\hline \multirow[t]{2}{*}{$\begin{array}{c}\text { LUX } \\
\text { Lung7 }\end{array}$} & Afatinib & 160 & 88.0 & 12.0 & 91.0 & 13.0 & 10.0 & 0 & 1.3 & 0.6 \\
\hline & Gefitinib & 159 & 61.0 & 1.0 & 61.0 & 1.0 & 25.0 & 9.0 & 0 & 0 \\
\hline \multirow[t]{2}{*}{ FLAURA } & Osimertinib & 279 & 58 & 1 & 58 & 2 & $9 / 6$ & $1 / 1$ & 4.0 & $\mathrm{NA}^{3}$ \\
\hline & Gef. or Erlo ${ }^{2}$ & 277 & 78 & 7 & 57 & 2 & $25 / 27$ & $4 / 8$ & 2.2 & $\mathrm{NA}^{3}$ \\
\hline
\end{tabular}

${ }^{1}$ Carbo/Pacli: carboplatin/paclitaxel, ${ }^{2}$ Gef. or Erlo: gefitinib or erlotinib, ${ }^{3}$ NA: not available.

\subsubsection{Diarrhea}

Diarrhea (all grades) associated with EGFR-TKI use is seen in 34-61\%, 51-58\%, 91\%, and $58 \%$ of patients treated with gefitinib, erlotinib, afatinib, and osimertinib, respectively (Table 1) $[14,16,20,24]$. Severe (grade 3 or 4 ) diarrhea is seen in 1-2.2\%, $2-3.3 \%, 13 \%$, and $2 \%$ of patients treated with gefitinib, erlotinib, afatinib, and osimertinib, respectively (Table 1) $[14,16,20,24]$. For diarrhea, orally administered loperamide $4 \mathrm{mg}$ is recommended in the early stage, and for continued episodes of loose stools, loperamide $2 \mathrm{mg}$ every $2 \mathrm{~h}$ is administered. In case of poor control, drug holidays and dose reduction should be considered.

\subsubsection{Elevated Liver Transaminases}

Elevated liver transaminases (all grades) associated with EGFR-TKI use are seen in $25-55 \%, 27-38 \%, 10 \%$, and $9 \%$ of patients treated with gefitinib, erlotinib, afatinib, and osimertinib, respectively (Table 1) [14,16,20,24]. Severely (grade 3 or 4) elevated liver transaminases is seen in $8-26 \%, 3.3-8 \%, 0 \%$, and $1 \%$ of patients treated with gefitinib, erlotinib, afatinib, and osimertinib, respectively (Table 1) $[14,16,20,24]$. Liver disorders are often improved with dose reduction or transient discontinuation of EGFR-TKIs, and/or concomitant use of hepatoprotective agents. Re-administration of EGFR-TKIs often exacerbates liver dysfunction and, in such cases, patients should be switched to other EGFR-TKIs. 


\subsubsection{Interstitial Lung Disease}

Initially, for gefitinib, which was the first approved EGFR-TKI for NSCLC treatment, the AEs were limited to relatively minor events, such as skin disorders. At a time when PCR analysis was not commonly used as a clinical test for detecting EGFR mutations, gefitinib was routinely used non-selectively in NSCLC patients as a safe treatment with orally available tablets. However, after the widespread use of this drug in clinical practice, it was revealed that fatal ILD may be a serious AE caused by gefitinib. The emergence of gefitinib-associated ILD was marked by a lawsuit over drug-induced suffering and was treated as a social problem in Japan. However, in Western countries, where the response rate of NSCLC to gefitinib was relatively low, this drug was not as widely used as in Asian countries. Therefore, in Western countries, ILD, which has a relatively low incidence, has not received much attention, and no large-scale survey has been conducted. However, ILD has been identified as an AE caused by all generations of EGFR-TKIs, and the frequency of treatment-related death is highest with this AE; therefore, ILD is considered to be a non-negligible AE (Table 1) [14,16,20,24]. As with other drug-induced ILDs, the molecular mechanisms of ILD induced by EGFR-TKIs have not been elucidated so far, and the coping method is limited to the use of empirical corticosteroid therapy. Clinical and observational studies in the real-world setting for evaluating EGFR-TKI-related ILD risk factors have been reported. To date, the listed risk factors include male sex, age $\geq 55$ years, Eastern Cooperative Oncology Group (ECOG)-Performance Status (PS) $\geq 2$, presence of contralateral lung metastases, history of radiation therapy within 1 year, smoking history, early treatment initiation after diagnosis, pre-existing interstitial pneumonia (IP), chronic obstructive pulmonary disease (COPD), lung infectious disease, coexisting heart disease, and normal lung area $<50 \%$ [26-29]. Among these, pre-existing IP was reported as an independent risk factor, and the incidence of gefitinib-induced ILD was significantly higher in this cohort than in the control group $(13.9 \%$ vs. $3.8 \%, p=0.013)$ [30].

\section{Preclinical Studies of EGFR-TKI Related Lung Injury}

The mechanisms of drug-induced lung injury after EGFR-TKI administration are unknown. As mentioned above, EGFR-TKIs block EGFR phosphorylation, thus preventing the regeneration and proliferation of the injured epithelium. This interruption of damagerepair mechanisms by EGFR activation may result in fatal EGFR-TKI-induced lung injury. The clinical features of lung injury induced by EGFR-TKI were identified as pre-existing pulmonary fibrosis, poor PS, and previous thoracic radiation, which were found to be independent risk factors in Japanese NSCLC patients [31]. Moreover, gefitinib-induced ILD was significantly associated with male sex, a history of tobacco use, and the co-occurrence of IP [30]. From these risk factors, it could be speculated that chronic inflammatory conditions in pulmonary tissues could be related to the occurrence of EGFR-TKI-induced lung injury. Most of the pathogenetic mechanisms by which EGFR-TKI-induced lung injury is unknown, although many challenges have been reported in the preclinical and clinical settings.

Preclinically, a murine model of bleomycin-induced pulmonary fibrosis has been employed for detecting the effect of EGFR-TKIs in pulmonary tissue. Suzuki et al. reported that gefitinib treatment of mice augments bleomycin-induced fibrosis. Following 3 weeks of gefitinib administration, severe fibrosis and collagen deposition were observed in the Institute of Cancer Research (ICR) mice that received both bleomycin and the EGFR-TKI, gefitinib, as compared to mice that received bleomycin and vehicle. The mechanisms underlying the augmentation of fibrosis through the inhibition of EGFR tyrosine kinase were unclear; however, it can be suggested that EGFR-TKIs might stimulate apoptosis of alveolar epithelial cells or inhibit epithelial cell differentiation and pulmonary angiogenesis [32]. In contrast, Ishii et al. reported that the EGFR-TKI gefitinib prevented bleomycin-induced lung fibrosis in a C57BL/6 mouse model. Immunohistochemical staining with a fibroblastspecific marker of the S100A4 antibody showed that gefitinib treatment inhibited the EGFR phosphorylation of fibroblasts and significantly decreased fibroblast proliferation, which was induced by bleomycin [33]. In these two research groups, there were no significant dif- 
ferences between the experimental methods, except for the difference in the mice variants used: ICR and C57BL/6. The reason for the discrepancy between these results is unknown.

Recently, a study using a bleomycin-induced lung fibrosis model showed that metformin attenuated gefitinib-induced exacerbation through the inhibition of TGF- $\beta$ signaling [34]. Male Sprague-Dawley rats were used for this experiment. Metformin is used to treat type II diabetes, and reduces glycogenesis through adenosine monophosphateactivated kinase (AMPK) signaling, thereby increasing glucose uptake in muscle cells in patients with diabetes, which leads to a decrease in glucose and insulin levels [35]. The rat lungs exhibited fibrosis following intratracheal injection of bleomycin and exacerbation of lung fibrosis by gefitinib administration for 3 weeks. Interestingly, metformin attenuated gefitinib-induced exacerbation of lung fibrosis and collagen deposition. This effect might be associated with a decrease in metformin-mediated activation of TGF- $\beta$ signaling. In this context, IL-6, which is produced downstream of TGF- $\beta$ activation, might contribute to the development of acute lung injury [36]. IL-6-deficient mice showed attenuated inflammatory cell (such as macrophages and neutrophils) accumulation after bleomycin administration compared to wild-type mice [37]. Furthermore, EGFR-TKI treatment increased IL-6 secretion in cancer cells, suggesting aggravation of lung injury [38].

Previously, a naphthalene-induced lung injury model was employed to investigate the effect of EGFR-TKI and gefitinib on airway injury and repair. Naphthalene is an aromatic hydrocarbon with Clara cell-selective cytotoxicity. Clara cells, also known as club cells, represent the major secretory cells of the small-airway epithelium in the lung, and play important protective roles through immune modulation, oxidative stress reduction, and metabolism of xenobiotics [39-41]. In this study, C57BL/6J mice were injected intraperitoneally with naphthalene, and gefitinib was orally administered for 7 and 14 days, respectively [42]. Naphthalene alone induced neutrophil infiltration at Day 7 but not on Day 14 in the lung tissue, whereas gefitinib administration after naphthalene treatment worsened neutrophil recruitment and acute lung injury was prolonged even on Day 14 Importantly, the terminal epithelial cells were retrieved with laser capture microdissection and gene expression was analyzed using a microarray. Then, 17 genes were determined to have a more than three-fold increase in the bronchiolar epithelial cells obtained from mice gefitinib/naphthalene at Day 14 compared to that from the naphthalene-alone mice. The genes were associated with neutrophil sequestration, acute inflammation, and airway remodeling, such as S100AB, S100A6, and StefinA3. Therefore, the suppression of EGFR signaling leads to the modulation of the expression of pro-inflammatory molecules in the repairing of airway epithelial cells.

Even with a bleomycin- or naphthalene-induced lung fibrosis/injury model, the best animal model should use EGFR-TKI alone to induce pulmonary injury or fibrosis. Previously, the authors used surfactant protein-C tumor necrosis factor transgenic (SPC-TNF tg) mice to test EGFR-TKI-induced lung injury. In this study, the authors hypothesized that EGFR can be transactivated by many types of extracellular stimuli, such as antagonists of Gprotein-coupled receptors (GPCR), cytokines, and cytokine receptors [43]. Tumor necrosis factor (TNF), interleukin (IL)-1 $\beta$, IL-8, IL-13, and interferon (INF)- $\gamma$ have been reported to transactivate EGFR in pulmonary epithelial cells through their cytokine receptors [44-46]. Therefore, EGFR transactivation through these cytokines might regulate multiple aspects of pulmonary cell homeostasis in response to injury. TNF is a pro-inflammatory cytokine that regulates many biological properties, such as cell survival, apoptosis, proliferation, and migration, in various types of tissues [47]. The downstream signals overlap between EGFR and TNF. TNF, in itself, is not a ligand for EGFR, although TNF stimulates EGFR phosphorylation through EGFR ligands in a dependent or independent manner. Several EGFR ligands are cleaved from the cell surface through the TNF- $\alpha$-converting enzyme (TACE; also called the disintegrin and metalloproteinase domain-containing protein 17 (ADAM17)) through the process of ectodomain shedding [48]. The TACE-mediated release of EGFR ligands is considered essential for EGFR activation. Cells from the human lung epithelial cell line BEAS-2B showed EGFR transactivation induced by TNF via the 
cleavage of heparin-binding (HB)-EGF by TACE and were protected from TNF-induced apoptosis [49]. EGFR and HER2 transactivated by TNF promote the survival response of colon epithelial cells through Src-kinase activity [46]. These findings indicate an important relationship between EGFR and TNF signals and epithelial cell survival in the cytokine-rich environment of acute injury response. Moreover, TNF knockout protects against bleomycin-induced lung fibrosis [50]. Therefore, we tested whether EGFR-TKIs enhance the development of lung injury in TNF-overexpressing lung tissues by inhibiting TNF-induced EGFR transactivation. SPC-TNF transgenic mice, a variant generated by Dr. Vasalli in 1995, were used, and transgenic TNF on the SPC promoter was overexpressed only in lung tissue and consequently resulted in alveolitis, alveolar disruption, and subsequent fibrogenesis in lung tissue [51]. Our results demonstrated that gefitinib remarkably enhanced lung inflammation and significant apoptosis induction that were mediated via the p38 MAPK pathway, as observed in SPC-TNF Tg mice. This indicates that EGFR-TKI disrupts the balance of cell survival in TNF-rich conditions through protein kinase B (AKT) and Extracellular Signal-regulated Kinase (ERK)1/2 inhibition as well as the activation of p38 MAP kinase (Figure 1). EGFR-TKIs are administered to patients with NSCLC who had EGFR-activating mutations, and careful attention should be paid to patients with COPD, pneumonitis, pneumonia, and inflammatory cytokine-enriched circumstances when selecting EGFR-TKI treatment.

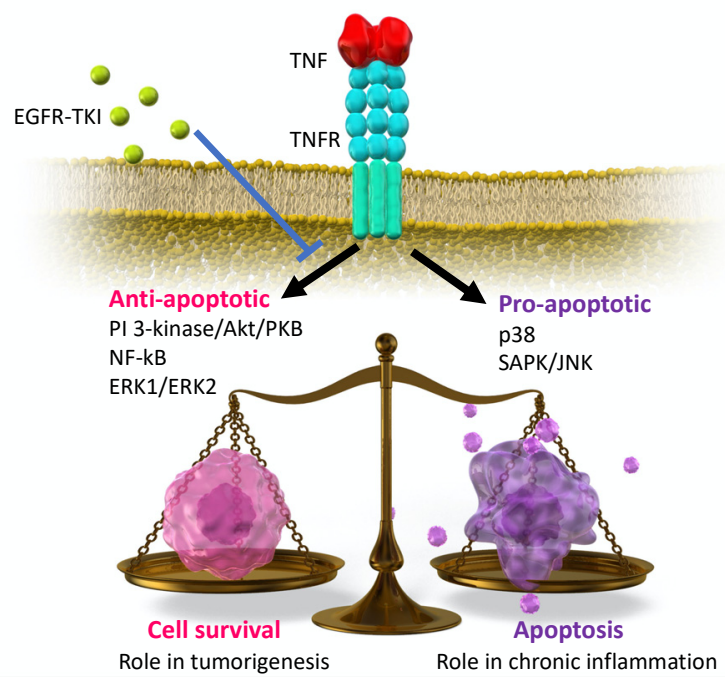

Figure 1. Schematic image of the downstream signaling of tumor necrosis factor (TNF); the balanced regulation of cell survival.

Despite the accumulating data and knowledge of EGFR-TKI-related pneumonitis, many issues remain to be solved. The pathophysiology of EGFR-TKI-related pneumonitis has not been elucidated, although a recent observation from a clinical combination trial of a novel immune-checkpoint inhibitor (ICI) and third-generation EGFR-TKI, Osimertinib, raised concerns with regard to lung toxicity [52]. A programmed death-ligand 1 (PDL1) inhibitor, durvalumab, plus osimertinib in patients with EGFR-mutation positive NSCLC indicated a significantly high rate of lung toxicity, with an incidence of $22 \%$ (affecting five out of 23 patients). In addition, patients with advanced NSCLC who were previously treated with nivolumab, a programmed death-1 (PD-1) inhibitor, developed severe pneumonitis during EGFR-TKI administration [53]. These observations may indicate that some suggested mechanisms of EGFR-TKI-related lung injury/fibrosis and further studies are required to determine the risk of combination therapy or sequential use of ICIs and EGFR-TKIs. The underlying mechanisms might involve cell-mediated autoimmune reaction or T-cell-mediated delayed hypersensitivity in ICI, or EGFR-TKI-related lung toxicity $[54,55]$. Moreover, the disruption of lung remodeling and the impaired response 
to injury were limited by EGFR-TKIs. These possible mechanisms are complicated by the modification of various host and environmental factors.

\section{Inflammatory Cytokines on EGFR-TKI Resistance}

\subsection{Expression of Inflammatory Cytokines on EGFR-TKI Resistance}

Previous studies have evaluated the association between inflammatory cytokines and EGFR-TKI resistance. For example, a head and neck cancer study reported that neutralization of IL-1M overcame erlotinib resistance in vivo, indicating that blocking IL-1 and downstream signaling could block the development of erlotinib resistance [56]. Moreover, experimental studies in colorectal cancer have found that elevated production of IL-1A, IL-1B, and IL-8, some of the inflammatory cytokines, is associated with increased resistance to cetuximab [57]. Therefore, evaluating the expression levels of these inflammatory cytokines in tumor specimens prior to treatment initiation may help clinicians predict the therapeutic efficacy.

Another study reported that IL-22 positively correlated with acquired resistance to EGFR-TKI in NSCLC patients with EGFR mutations [58]. Moreover, IL-22 has been shown to induce gefitinib resistance both in vitro and in vivo, indicating that IL-22 induction within the tumor microenvironment complicates the acquired EGFR-TKI-resistance in NSCLC [58].

A study of PC-9, a gefitinib-sensitive NSCLC cell line, investigated whether IL-8 was associated with resistance to gefitinib and found that, in addition to IL-8, an IL-8-specific receptor, C-X-C motif chemokine receptor 1 (CXCR1) was significantly upregulated in this cell line. Together, these results suggest that IL-8-CXCR1/2 signaling is associated with gefitinib resistance [59], thus providing a possible mechanism whereby high plasma IL-8 levels mediate PFS in EGFR TKI-treated patients with EGFR mutation-positive lung adenocarcinoma.

Results of previous studies have shown that the clinical outcome of EGFR-TKI treatment is related to the levels of inflammatory cytokines, including plasma IL-8, IL-10, and regulated upon activation, normal T-cell expressed and secreted (RANTES), at the time of diagnosis [60].

We previously examined the relationship between acquired resistance to EGFR-TKI and TNF sensitivity in NSCLC cell lines and found that, with regard to the EGFR-sensitive mutation, a gefitinib-resistant cell line was $\sim 67$ times more sensitive to TNF- $\alpha$ than the gefitinib-sensitive cell line. Strikingly, cell lines that regained their resistance to gefitinib had a sensitivity to TNF- $\alpha$ similar to that of the gefitinib-sensitive cell line, suggesting that the sensitivity to TNF- $\alpha$ correlated with gefitinib resistance [61]. In addition, a recent study reported that inhibiting TNF signaling in NSCLC cell lines with EGFR-sensitive mutations increased their sensitivity to EGFR-TKI [62].

The results of these studies indicate that a clear relationship exists between inflammatory cytokines and resistance to EGFR-TKI. Thus, understanding the mechanisms that underpin this relationship may help overcome EGFR-TKI resistance.

\subsection{Possible EGFR-TKI Resistance Mechanisms in Inflammation}

Previous studies have examined the possible mechanisms underlying EGFR-TKI resistance in an inflamed state. For example, studies have shown that Akt phosphorylation is elevated in cells that overexpress IL-8 compared to those with the control condition. The phosphoinositide 3-kinase (PI3K)/AKT pathway has been reported as one of the pivotal downstream effectors of IL-8 signaling and is known to cause tumor progression [63]. Moreover, tumor development may occur via IL-8-initiated activation of CXCR1/2 signaling, leading to activation of NF- $\mathrm{KB}$, which in turn promotes further tumor development [59]. This signaling cascade is associated with IL-8 overexpression-induced EGFR-TKI resistance.

Another study found that IL-22 exposure increased the expression levels of phosphorylated-AKT, EGFR, and ERK in the tumor microenvironment after gefitinib treatment versus the control group [58]. 
We previously examined the association between increased sensitivity to TNF- $\alpha$ and mechanisms of acquired resistance to gefitinib [61]. Our results demonstrated that PI3K/AKT signaling in a gefitinib-sensitive cell line was attenuated by gefitinib in a concentration-dependent manner, whereas PI3K/AKT signaling was unaffected by gefitinib in a gefitinib-acquired resistant cell line. These results suggest that activation of the PI3/AKT signaling by TNF was primarily mediated by constitutive crosstalk signaling from the tumor necrosis factor receptor (TNFR) to EGFR rather than by the direct stimulation from TNFR to PI3/AKT signaling [61]. Therefore, we believe that the increased sensitivity of gefitinib-acquired resistant strains to TNF- $\alpha$ is caused by decreased TNFR-to-EGFR crosstalk signaling, which in turn may enhance TNF-dependent apoptosis (Figure 2).

The crosstalk signaling from TNFR to EGFR is constitutively activated and plays a central role in mediating TNF-activated anti-apoptotic effects via AKT signaling in NSCLC lines with EGFR-sensitive mutations. This crosstalk between TNFR and EGFR is diminished in cell lines that have acquired resistance to gefitinib. In such cases, cells with acquired resistance to gefitinib are sensitive to TNF and are vulnerable to TNF-induced apoptosis.

A recent study showed that suppression of TNF/NFKB signaling in EGFR-sensitive cell lines affected the sensitivity of EGFR to inhibition, supporting the results of our previous studies [62].

In summary, multiple reports have provided evidence of the relationship between the activation of inflammatory cytokines and the resistance of cancer cells to EGFR-TKIs. Further exploration of the role of inflammatory cytokines in EGFR-TKI resistance could possibly unravel some of the mechanisms by which EGFR-TKI resistance occurs in cancer cells. Further systemic studies incorporating the assessment of inflammatory cytokines could lead to therapeutic strategies that overcome EGFR-TKI resistance.

\section{The mechanism(s) of EGFR transactivation by TNF}

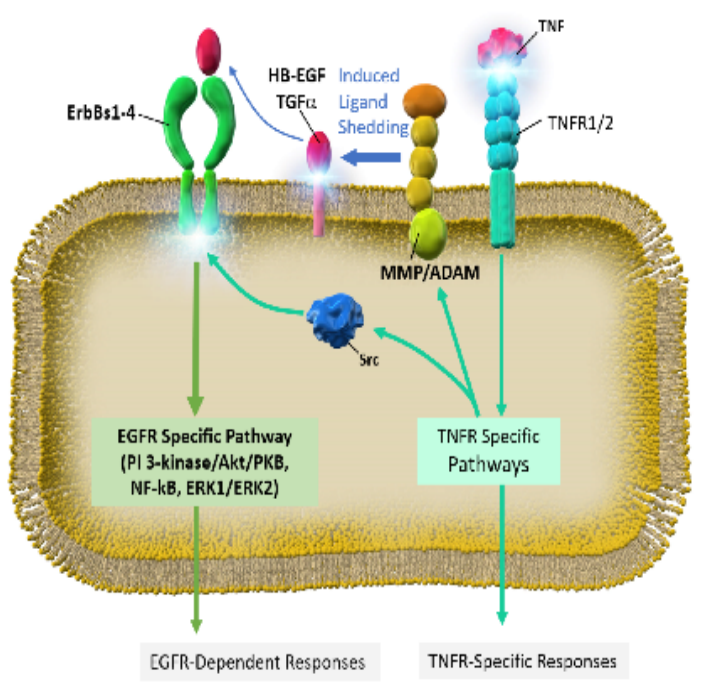

Figure 2. TNF-induced anti-apoptotic cell signaling via tumor necrosis factor receptor (TNFR) to EGFR crosstalk signaling.

\section{Clinical Studies of EGFR-TKI-Related Lung Injury}

Here, we present the results of meta-analysis and clinical trials reported so far with regard to the incidence of ILD when there is: (1) EGFR-TKI monotherapy, (2) a combination of EGFR-TKIs and other chemotherapeutic agents, and (3) a combination of EGFR-TKIs and immune checkpoint inhibitors (ICIs).

\subsection{EGFR-TKI Monotherapy}

Until now, various EGFR-TKI clinical trials have been conducted, and AEs have been investigated in detail. Meta-analyses that included many clinical studies have reported 
the occurrence of ILD $[14,16,23]$. The databases of these reports are partially duplicated, as shown in Table 2; however, when racial differences are not taken into account, the incidence of all grades of ILD with EGFR-TKI monotherapy is generally consistent at $1.1-2.2 \%$. The incidence of grade 3 or higher ILD (severe symptoms or oxygen supplemental cases) is $0.6-1.0 \%$ and of grade 5 (mortality) AE is $0.2-0.5 \%$. ILD is the most frequent cause of EGFR-TKI-treatment-related death, accounting for $58 \%$ of cases [14]. There are no reports of a significant difference in the incidence of ILD between EGFR-TKIs (gefitinib 1.3-2.2\%, erlotinib $0.6-1.5 \%$, afatinib $0.2-0.6 \%$, and osimertinib $3.0 \%$ ) $[14,16,23]$.

With regard to racial differences, the incidence of ILD is especially high in the data from Japan. Suh et al. compared research data from Japan and other countries and found that the ILD incidence in Japanese patients was significantly higher, $4.8 \%$ vs. $0.6 \%(p<0.001)$ for all grades, $2.5 \%$ vs. $0.4 \%(p<0.001)$ for grade $\geq 3$, and $1.0 \%$ vs. $0.2 \%$ for grade 5 AEs $(p<0.001)$ [64]. In contrast, when comparing Asian countries, excluding Japanese participants with non-Asians, no significant difference was observed. The reason for the high incidence of ILD in the Japanese population is being analyzed with regard to proteomic [65] and genetic polymorphisms (NEJ022A; UMIN ID: UMIN000015612), although an underlying cause has not been clarified until now. As mentioned earlier, after the occurrence of gefitinib-induced ILD emerged as a social problem in Japan and was evaluated in many clinical studies in Japan as compared to that in other countries, Japanese oncologists have specifically focused on the AE of ILD, and the high incidence may be partly attributable to the high frequency of CT examinations (the number of Japanese CTs per million people is the highest worldwide [66]. Moreover, the lack of quantitative and qualitative international criteria for IP may be a factor, although the diagnostic guideline for idiopathic pulmonary fibrosis (IPF), which represents a collaborative effort between American Thoracic Society (ATS)/European Respiratory Society (ERS)/ Japanese Respiratory Society (JRS)/Latin America Thoracic Association (ALAT), has been issued in 2018 [67].

Table 2. Incidence of interstitial lung disease (ILD) on EGFR-TKI treatment in meta-analysis.

\begin{tabular}{|c|c|c|c|c|c|}
\hline Author & Patients & Treatments & ILD Incidence (\%) & Japanese ILD Incidence (\%) & Reference \\
\hline Suh et al. & 15,713 & Gef. ${ }^{1}$, Erlo. ${ }^{2}$, Afa. ${ }^{3}$, Osim. ${ }^{4}$ & 1.1 & 4.8 & {$[64]$} \\
\hline Shi et al. & 8609 & Gef. $^{1}$, Erlo. ${ }^{2}$ & 1.2 & 3.3 & [68] \\
\hline Takeda et al. & 1468 & Gef. ${ }^{1}$, Erlo. ${ }^{2}$, Afa. ${ }^{3}$ & $0.6-2.2$ & 3.8 & [22] \\
\hline
\end{tabular}

\subsection{Combination of EGFR-TKIs and Chemotherapeutic Agents or Angiogenesis Inhibitors}

Clinical trial results have been reported on the incidence of ILD when EGFR-TKIs are used in combination with other chemotherapeutic drugs. Hosomi et al. reported that the incidence of ILD in patients receiving carboplatin (CBDCA) + pemetrexed (PEM) + gefitinib was $6 \%$ for all grades and $2.4 \%$ for grade $\geq 3$ AEs, and the incidence of AEs with gefitinib monotherapy was 3.5\% for all grades and 0.6\% for grade $\geq 3$ AEs in Japan (NEJ009) [69]. With the determination of the incidence of IP by PEM monotherapy in NSCLC patients at $2.6 \%$ in Japan, the combined use of EGFR-TKI and CBDCA + PEM may increase the incidence of ILD compared to EGFR-TKI monotherapy. In contrast, Noronha et al. similarly compared the AE incidence in CBDCA + PEM + gefitinib-administered patients with those of the gefitinib-alone group and found no significant difference in ILD incidence [70].

The incidence of ILD in erlotinib + bevacizumab [71-73] and erlotinib + ramucirumab [74] was investigated in patients receiving combination therapy with angiogenesis inhibitors and EGFR-TKIs. None of the patients showed a significant increase in ILD incidence compared to that with erlotinib monotherapy.

\subsection{Combination of EGFR-TKIs and ICIs}

The combination of ICIs with chemotherapeutic drugs has been shown to be effective. In this context, a phase I clinical trial of the anti-programmed death-ligand-1 antibody, 
durvalumab, and osimertinib combination was conducted $[10,75]$. When osimertinib was combined with durvalumab 3 or $10 \mathrm{mg} / \mathrm{kg}$, the incidence of ILD was as high as $22 \%$ for all grades and $8.7 \%$ for grade $\geq 3$ AEs; however, due to the increasing reports of ILD, the clinical trial (TATTON) was terminated. The trial enrolled a relatively small number of patients; however, we infer that combination therapy with EGFR-TKIs and ICIs may increase the incidence of ILD, and development of the combination therapy regimens should be carefully evaluated (Table 3).

Table 3. Incidence of ILD in the combined therapy with EGFR-TKIs.

\begin{tabular}{ccccc}
\hline \multicolumn{5}{c}{ ILD } \\
\hline Trial & Drugs & ALL (\%) & $\geq$ G3 (\%) & Reference \\
\hline NEJ009 & CBDCA $^{1}+$ PEM $^{2}+$ Gefitinib & $11 / 170(6.5 \%)$ & $4 / 170(2.4 \%)$ & {$[69]$} \\
& Gefitinib & $6 / 171(3.5 \%)$ & $1 / 171(0.6 \%)$ & \\
\hline NEJ026 & Erlotinib + Bevacizumab & $0 / 112(0 \%)$ & $0 / 121(0 \%)$ & {$[71]$} \\
& Erlotinib & $5 / 114(4.4 \%)$ & $0 / 114(0 \%)$ & \\
\hline RELAY & Erlotinib + Ramucirumab & $3 / 221(1.4 \%)$ & $1 / 221(0.5 \%)$ & {$[74]$} \\
& Erlotinib & $4 / 225(1.8 \%)$ & $2 / 225(0.9 \%)$ & \\
\hline TATTON & Osimertinib + Durvalumab & $5 / 23(22 \%)$ & $2 / 23(8.7 \%)$ & {$[75]$} \\
\hline
\end{tabular}

${ }^{1}$ CBDCA: carboplatin, ${ }^{2}$ PEM: pemetrexed.

\section{Diagnosis and Therapeutics of EGFR-TKI-Related Lung Injury}

\subsection{Diagnosis}

EGFR-TKI-related lung injury, otherwise known as ILD, induced by EGFR-TKI, is a rare but fatal $\mathrm{AE}$. The diagnosis is based on clinical suspicion during EGFR-TKI treatment, detection of lung parenchymal infiltration on radiological assessment, and diagnostic exclusion of tumor progression, cardiac diseases, or other pulmonary complications, such as infectious pneumonitis [55,76].

The clinical symptoms of EGFR-TKI-induced ILD include cough, fever, exertional dyspnea, and other respiratory symptoms. As these are non-specific symptoms, and the symptom onset occurs in a wide range of conditions, it is difficult to distinguish ILD from other respiratory diseases. Furthermore, the findings on physical examination are nonspecific, although chest auscultation and consideration of other findings, such as peripheral edema, could facilitate the exclusion of a diagnosis of cardiac pulmonary edema $[55,76]$.

In general, chest roentgenography is the first step in the radiological assessment of pulmonary diseases, including ILD. However, the findings are nonspecific and sometimes almost normal in early-stage disease. High-resolution CT (HRCT) of the chest is used in the second step of a diagnostic workup of ILD [55,76], and the findings provide information about not only the distribution pattern but also the abnormalities of the parenchymal pulmonary pattern, which is possibly correlated with the histologic pattern of ILD [77]. Endo et al. analyzed imaging data and clinical manifestations of cases of acute ILD caused by gefitinib, and proposed four radiological patterns based on chest roentgenogram and HRCT (Table 4) [78]. Furthermore, this report showed the incidence of these four patterns that correspond to ILD patterns that reflect a higher mortality risk [78]. An HRCT of the chest should be obtained before the initiation of EGFR-TKI therapy because pre-existing pulmonary abnormalities, such as lung fibrosis, are associated with an increased risk of ILD [30]. Serial assessment of HRCT during EGFR-TKI treatment is helpful for the early detection of ILD-related changes. However, HRCT assessment is not comprehensive because the findings on HRCT of EGFR-TKI-induced ILD are similar to those of other pulmonary complications, such as Pneumocystis jirovecii pneumonitis (PCP), cytomegalovirus, and coronavirus disease 2019 (COVID-19) infection [79]. Additionally, patients receiving EGFR-TKIs could be immunocompromised and have a higher risk of infection because of advanced cancer, which can lead to a wrong diagnosis. 
Laboratory tests, including complete blood cell counts and biochemical analysis, have been routinely conducted in patients suspected to be at risk for developing ILD. Krebs von den Lungen-6 (KL-6) is a high-molecular weight glycoprotein that is classified as human MUC1 mucin [80]. Elevation of serum KL-6 levels is significantly correlated with various lung diseases such as lung fibrosis and radiation pneumonitis [80,81]. However, evaluating the absolute level of KL-6 in serum is insufficient to diagnose drug-induced ILD [82]. Kawase et al. demonstrated that the degree of elevation of KL-6 from baseline could predict the disease severity as well as the clinical prognosis [83]. Therefore, it is essential to evaluate serum KL-6 levels before the initiation of EGFR-TKI treatment, and close monitoring is necessary during the therapy.

Bronchoscopy is useful to obtain direct information about lung parenchymal abnormalities. However, the main aim of the examination is to exclude infectious pneumonitis and disease progression, and not to confirm the pattern of ILD [84].

Table 4. Four proposed radiological patterns based on chest roentgenogram and high-resolution CT (HRCT) on acute ILD caused by gefitinib.

\begin{tabular}{|c|c|c|c|c|c|}
\hline Pattern & $\begin{array}{c}\text { Findings on } \\
\text { Roentgenography }\end{array}$ & Manifestations on CT Scan & $\begin{array}{l}\text { Corresponding } \\
\text { Pattern of ILD }\end{array}$ & Incidence $(\%)$ & Mortality (\%) \\
\hline $\mathrm{A}$ & $\begin{array}{l}\text { Diffuse and faint opacity } \\
\text { without volume loss }\end{array}$ & $\begin{array}{l}\text { Non-specific area: } \\
\text { Ground-glass opacity }\end{array}$ & $\mathrm{NSIP}^{1}$ & 47.1 & 31.0 \\
\hline B & Peripheral consolidation & $\begin{array}{l}\text { Multifocal area: Airspace } \\
\text { consolidation }\end{array}$ & $\mathrm{OP} / \mathrm{BOOP}^{2}$ & 13.7 & 28.6 \\
\hline $\mathrm{C}$ & $\begin{array}{l}\text { Patchy or diffuse faint, } \\
\text { liner opacities }\end{array}$ & $\begin{array}{c}\text { Patchy distribution area: } \\
\text { Ground-glass opacity } \\
\text { interlobular septal thickening }\end{array}$ & $\mathrm{AEP}^{3}$ & 2.0 & 0.0 \\
\hline $\mathrm{D}$ & $\begin{array}{l}\text { Diffuse faint opacity or } \\
\text { consolidation with } \\
\text { volume loss }\end{array}$ & $\begin{array}{l}\text { Extensive bilateral area: } \\
\text { Ground-glass opacities; air } \\
\text { space consolidation with } \\
\text { traction bronchiectasis }\end{array}$ & $\mathrm{AIP}^{4}$ & 23.5 & 75.0 \\
\hline Others & Non-specific & Non-specific & $\mathrm{N} / \mathrm{A}$ & 13.7 & 45.5 \\
\hline
\end{tabular}

\subsection{Therapeutics}

These are no standard guidelines, and no specific therapies have been established for the management of EGFR-TKI-related ILD. Withdrawal of EGFR-TKI treatment is essential in all cases, and supportive treatments with oxygen supplementation are required in patients with respiratory failure. Corticosteroids have been widely used in patients with ILD to control excessive pulmonary inflammation [55,76]. Treatment combining EGFRTKIs with corticosteroids was successful among patients with NSCLC who experienced ILD induced by EGFR-TKIs [85]. However, such cases were restricted in mild ILD, had nondiffuse alveolar damage (DAD) patterns, and responded well to corticosteroid therapy. On the other hand, it was reported that cases with EGFR-TKI-induced ILD that did not respond to a moderate dose of corticosteroid could have improved with high-dose corticosteroid therapy [86]. High-dose corticosteroid therapy consisted of $500 \mathrm{mg} /$ day, up to $1 \mathrm{~g} /$ day, of intravenous methylprednisolone for 3 days. Thereafter, corticosteroids were reduced to a maintenance dose ( 0.5 to $1 \mathrm{~g} / \mathrm{kg} /$ day of oral prednisolone). The daily dose of oral prednisolone was decreased by $5-10 \mathrm{mg} /$ week, depending on the patient's response.

The cytokine interleukin-6 (IL-6) plays a critical role in the inflammatory process and is implicated in the development of severe acute respiratory syndrome [87]. A preclinical investigation demonstrated that EGFR-TKI administration not only decreased the viability of cancer cells, but also increased IL-6 production from cancer cells [38]. The results indicated that EGFR-TKIs could induce ILD via IL-6 production [38]. Therefore, blocking 
IL-6 activity should be effective for controlling EGFR-TKI-induced ILD. The recombinant humanized anti-human IL-6 receptor monoclonal antibody tocilizumab is widely used for treating autoimmune diseases such as giant cell arthritis [88]. Currently, tocilizumab can achieve a clinical response in patients with severe respiratory failure caused by severe acute respiratory syndrome coronavirus 2 infection $[89,90]$. No clinical evidence was established in the area of drug-induced ILD; however, a similar pathogenesis should exist. Thus, tocilizumab may be effective in treating severe cases of EGFR-TKI-induced ILD.

In addition to the previously approved use of corticosteroids as the sole therapy for IPF, pirfenidone and nintedanib have been approved recently and used clinically for the treatment of IPF. In particular, nintedanib has been shown to prevent the development of acute IPF exacerbations [91]. The indications for these anti-fibrotic drugs are currently limited to IPF, although the preventive effect of these drugs with regard to acute exacerbation, due to surgery and chemotherapy, in lung cancer patients with pre-existing IPF is being investigated [92,93]. Kanayama et al. classified 100 patients with indications for surgery into three groups according to the surgical risk score and conducted a retrospective study on the incidence of IPF as an acute exacerbation in the pirfenidone-administered and control groups [92]. The results showed that the incidence of acute exacerbation was suppressed by pirfenidone in all groups. A randomized controlled study is currently underway to evaluate the effect of nintedanib for preventing acute IPF exacerbation during CBDCA + Nab-paclitaxel combination therapy for NSCLC patients with IPF [94]. Thus far, only case studies have reported the effects of anti-fibrotic drugs on EGFR-TKI-related ILD; however, a clinical study of this side effect of EGFR-TKI-related ILD has been planned and will finally help to develop a safer treatment regimen for EGFR-TKI-based therapy.

\section{Conclusions}

The tyrosine kinase activity of EGFR could be an invaluable target for the development of anticancer agents. EGFR-TKI have been developed for NSCLC patients carrying EGFRactivating mutations, such as 15 bp deletions in EGFR exon 19 or L858R mutation in EGFR exon 21. First-generation EGFR-TKIs (such as gefitinib and erlotinib) have exhibited promising survival benefits for NSCLC patients compared to the survival rates observed before EGFR-TKI approval.

However, acquired EGFR T790M mutations can occur as resistance to these EGFR-TKIs. Second-generation EGFR-TKIs (afatinib and dacomitinib) and third-generation EGFR-TKIs (osimertinib) have been developed to overcome such resistant EGFR mutations. Although the development of EGFR-TKIs and combination therapies with EGFR-TKIs are extensively progressive, resistance to EGFR-TKIs still occurs in NSCLC patients with EGFR-activating mutations. The clinical values of these EGFR-TKIs are yet to be completely understood. Furthermore, aberrant EGFR tyrosine kinase activity remains a promising target in cancer therapy.

The EGFR-TKI-induced lung injury occurred at a low frequency of $1.1-2.2 \%$, but it was caused by all generations of EGFR-TKIs and, furthermore, it was fatal, accounting for $58 \%$ of all treatment-related deaths of EGFR-TKIs. The risk factor profiles, such as smoking, coincidence of interstitial pneumonia, and COPD, can indicate the circumstances of chronic inflammation in pulmonary tissues. Therefore, the association between inflammatory cytokines and EGFR-TKIs could be involved in the occurrence or progression of EGFR-TKIinduced ling injury.

Understanding the role of EGFR in cytokine-rich circumstances, such as inflammation, can provide a promising therapeutic strategy to overcome EGFR-TKI-induced lung injury and resistance to EGFR-TKIs.

Author Contributions: Writing, T.O., T.Y., K.A., S.K., Y.K. and R.M.; Project Administration, H.S. All authors have read and agreed to the published version of the manuscript.

Funding: This work was supported in part by a Research Award from the Showa University School of Medicine Alumni Association. 
Institutional Review Board Statement: Not applicable.

Informed Consent Statement: Not applicable.

Data Availability Statement: Not applicable.

Acknowledgments: We thank the members of Division of Respiratory Medicine and Allergology, Department of Medicine, Showa University School of Medicine for their thoughtful discussions and helpful advice.

Conflicts of Interest: The authors declare no conflict of interest. The funding sponsors had no role in the choice of research project; design of the study; in the collection, analyses or interpretation of data; in the writing of the manuscript; or in the decision to publish the results.

\section{References}

1. Bray, F.; Ferlay, J.; Soerjomataram, I.; Siegel, R.L.; Torre, L.A.; Jemal, A. Global cancer statistics 2018: GLOBOCAN estimates of incidence and mortality worldwide for 36 cancers in 185 countries. CA Cancer J. Clin. 2018, 68, 394-424. [CrossRef]

2. Proto, C.; Ferrara, R.; Signorelli, D.; Lo Russo, G.; Galli, G.; Imbimbo, M.; Prelaj, A.; Zilembo, N.; Ganzinelli, M.; Pallavicini, L.M.; et al. Choosing wisely first line immunotherapy in non-small cell lung cancer (NSCLC): What to add and what to leave out. Cancer Treat. Rev. 2019, 75, 39-51. [CrossRef]

3. Yatabe, Y.; Kerr, K.M.; Utomo, A.; Rajadurai, P.; Tran, V.K.; Du, X.; Chou, T.Y.; Enriquez, M.L.; Lee, G.K.; Iqbal, J.; et al. EGFR mutation testing practices within the Asia Pacific region: Results of a multicenter diagnostic survey. J. Thorac. Oncol. 2015, 10, 438-445. [CrossRef]

4. Le, T.; Gerber, D.E. Newer-Generation EGFR Inhibitors in Lung Cancer: How Are They Best Used? Cancers 2019, 11, 366. [CrossRef]

5. Zhou, C.; Wu, Y.L.; Chen, G.; Feng, J.; Liu, X.Q.; Wang, C.; Zhang, S.; Wang, J.; Zhou, S.; Ren, S.; et al. Erlotinib versus chemotherapy as first-line treatment for patients with advanced EGFR mutation-positive non-small-cell lung cancer (OPTIMAL, CTONG-0802): A multicentre, open-label, randomised, phase 3 study. Lancet Oncol. 2011, 12, 735-742. [CrossRef]

6. Mok, T.S.; Wu, Y.L.; Ahn, M.J.; Garassino, M.C.; Kim, H.R.; Ramalingam, S.S.; Shepherd, F.A.; He, Y.; Akamatsu, H.; Theelen, W.S.; et al. Osimertinib or Platinum-Pemetrexed in EGFR T790M-Positive Lung Cancer. N. Engl. J. Med. 2017, 376, 629-640. [CrossRef]

7. Mok, T.S.; Wu, Y.L.; Thongprasert, S.; Yang, C.H.; Chu, D.T.; Saijo, N.; Sunpaweravong, P.; Han, B.; Margono, B.; Ichinose, Y.; et al. Gefitinib or carboplatin-paclitaxel in pulmonary adenocarcinoma. N. Engl. J. Med. 2009, 361, 947-957. [CrossRef]

8. Ren, S.; Li, Y.; Li, W.; Zhao, Z.; Jin, C.; Zhang, D. Fatal asymmetric interstitial lung disease after erlotinib for lung cancer. Respiration 2012, 84, 431-435. [CrossRef]

9. Schacher-Kaufmann, S.; Pless, M. Acute Fatal Liver Toxicity under Erlotinib. Case Rep. Oncol. 2010, 3, 182-188. [CrossRef]

10. Takeda, M.; Okamoto, I.; Tsurutani, J.; Oiso, N.; Kawada, A.; Nakagawa, K. Clinical impact of switching to a second EGFR-TKI after a severe AE related to a first EGFR-TKI in EGFR-mutated NSCLC. Jpn. J. Clin. Oncol. 2012, 42, 528-533. [CrossRef]

11. Berge, E.M.; Doebele, R.C. Targeted therapies in non-small cell lung cancer: Emerging oncogene targets following the success of epidermal growth factor receptor. Semin. Oncol. 2014, 41, 110-125. [CrossRef]

12. Miller, V.A.; Hirsh, V.; Cadranel, J.; Chen, Y.M.; Park, K.; Kim, S.W.; Zhou, C.; Su, W.C.; Wang, M.; Sun, Y.; et al. Afatinib versus placebo for patients with advanced, metastatic non-small-cell lung cancer after failure of erlotinib, gefitinib, or both, and one or two lines of chemotherapy (LUX-Lung 1): A phase 2b/3 randomised trial. Lancet Oncol. 2012, 13, 528-538. [CrossRef]

13. Cross, D.A.; Ashton, S.E.; Ghiorghiu, S.; Eberlein, C.; Nebhan, C.A.; Spitzler, P.J.; Orme, J.P.; Finlay, M.R.; Ward, R.A.; Mellor, M.J.; et al. AZD9291, an irreversible EGFR TKI, overcomes T790M-mediated resistance to EGFR inhibitors in lung cancer. Cancer Discov. 2014, 4, 1046-1061. [CrossRef]

14. Maemondo, M.; Inoue, A.; Kobayashi, K.; Sugawara, S.; Oizumi, S.; Isobe, H.; Gemma, A.; Harada, M.; Yoshizawa, H.; Kinoshita, I.; et al. Gefitinib or chemotherapy for non-small-cell lung cancer with mutated EGFR. N. Engl. J. Med. 2010, 362, 2380-2388. [CrossRef]

15. Mitsudomi, T.; Morita, S.; Yatabe, Y.; Negoro, S.; Okamoto, I.; Tsurutani, J.; Seto, T.; Satouchi, M.; Tada, H.; Hirashima, T.; et al. Gefitinib versus cisplatin plus docetaxel in patients with non-small-cell lung cancer harbouring mutations of the epidermal growth factor receptor (WJTOG3405): An open label, randomised phase 3 trial. Lancet Oncol. 2010, 11, 121-128. [CrossRef]

16. Park, K.; Tan, E.H.; O’Byrne, K.; Zhang, L.; Boyer, M.; Mok, T.; Hirsh, V.; Yang, J.C.; Lee, K.H.; Lu, S.; et al. Afatinib versus gefitinib as first-line treatment of patients with EGFR mutation-positive non-small-cell lung cancer (LUX-Lung 7): A phase 2B, open-label, randomised controlled trial. Lancet Oncol. 2016, 17, 577-589. [CrossRef]

17. Paz-Ares, L.; Tan, E.H.; O’Byrne, K.; Zhang, L.; Hirsh, V.; Boyer, M.; Yang, J.C.; Mok, T.; Lee, K.H.; Lu, S.; et al. Afatinib versus gefitinib in patients with EGFR mutation-positive advanced non-small-cell lung cancer: Overall survival data from the phase IIb LUX-Lung 7 trial. Ann. Oncol. 2017, 28, 270-277. [CrossRef]

18. Wu, Y.L.; Cheng, Y.; Zhou, X.; Lee, K.H.; Nakagawa, K.; Niho, S.; Tsuji, F.; Linke, R.; Rosell, R.; Corral, J.; et al. Dacomitinib versus gefitinib as first-line treatment for patients with EGFR-mutation-positive non-small-cell lung cancer (ARCHER 1050): A randomised, open-label, phase 3 trial. Lancet Oncol. 2017, 18, 1454-1466. [CrossRef] 
19. Mok, T.S.; Cheng, Y.; Zhou, X.; Lee, K.H.; Nakagawa, K.; Niho, S.; Lee, M.; Linke, R.; Rosell, R.; Corral, J.; et al. Improvement in Overall Survival in a Randomized Study That Compared Dacomitinib With Gefitinib in Patients with Advanced Non-Small-Cell Lung Cancer and EGFR-Activating Mutations. J. Clin. Oncol. 2018, 36, 2244-2250. [CrossRef]

20. Soria, J.C.; Ohe, Y.; Vansteenkiste, J.; Reungwetwattana, T.; Chewaskulyong, B.; Lee, K.H.; Dechaphunkul, A.; Imamura, F.; Nogami, N.; Kurata, T.; et al. Osimertinib in Untreated EGFR-Mutated Advanced Non-Small-Cell Lung Cancer. N. Engl. J. Med. 2018, 378, 113-125. [CrossRef]

21. Ramalingam, S.S.; Vansteenkiste, J.; Planchard, D.; Cho, B.C.; Gray, J.E.; Ohe, Y.; Zhou, C.; Reungwetwattana, T.; Cheng, Y.; Chewaskulyong, B.; et al. Overall Survival with Osimertinib in Untreated, EGFR-Mutated Advanced NSCLC. N. Engl. J. Med. 2020, 382, 41-50. [CrossRef] [PubMed]

22. Takeda, M.; Okamoto, I.; Nakagawa, K. Pooled safety analysis of EGFR-TKI treatment for EGFR mutation-positive non-small cell lung cancer. Lung Cancer 2015, 88, 74-79. [CrossRef]

23. Nakahara, T.; Moroi, Y.; Takayama, K.; Itoh, E.; Kido-Nakahara, M.; Nakanishi, Y.; Furue, M. Changes in sebum levels and the development of acneiform rash in patients with non-small cell lung cancer after treatment with EGFR inhibitors. Onco Targets Ther. 2015, 8, 259-263. [CrossRef] [PubMed]

24. Urata, Y.; Katakami, N.; Morita, S.; Kaji, R.; Yoshioka, H.; Seto, T.; Satouchi, M.; Iwamoto, Y.; Kanehara, M.; Fujimoto, D.; et al. Randomized Phase III Study Comparing Gefitinib With Erlotinib in Patients with Previously Treated Advanced Lung Adenocarcinoma: WJOG 5108L. J. Clin. Oncol. 2016, 34, 3248-3257. [CrossRef] [PubMed]

25. Hirsh, V. Managing treatment-related adverse events associated with egfr tyrosine kinase inhibitors in advanced non-small-cell lung cancer. Curr. Oncol. 2011, 18, 126-138. [CrossRef]

26. Kudoh, S.; Kato, H.; Nishiwaki, Y.; Fukuoka, M.; Nakata, K.; Ichinose, Y.; Tsuboi, M.; Yokota, S.; Nakagawa, K.; Suga, M.; et al. Interstitial lung disease in Japanese patients with lung cancer: A cohort and nested case-control study. Am. J. Respir. Crit. Care Med. 2008, 177, 1348-1357. [CrossRef] [PubMed]

27. Gemma, A.; Kudoh, S.; Ando, M.; Ohe, Y.; Nakagawa, K.; Johkoh, T.; Yamazaki, N.; Arakawa, H.; Inoue, Y.; Ebina, M.; et al. Final safety and efficacy of erlotinib in the phase 4 POLARSTAR surveillance study of 10708 Japanese patients with non-small-cell lung cancer. Cancer Sci. 2014, 105, 1584-1590. [CrossRef] [PubMed]

28. Tamura, K.; Nukiwa, T.; Gemma, A.; Yamamoto, N.; Mizushima, M.; Ochai, K.; Ikeda, R.; Azuma, H.; Nakanishi, Y. Real-world treatment of over 1600 Japanese patients with EGFR mutation-positive non-small cell lung cancer with daily afatinib. Int. J. Clin. Oncol. 2019, 24, 917-926. [CrossRef]

29. Ohe, Y.; Kato, T.; Sakai, F.; Kusumoto, M.; Endo, M.; Saito, Y.; Baba, T.; Sata, M.; Yamaguchi, O.; Sakamoto, K.; et al. Real-world use of osimertinib for epidermal growth factor receptor T790M-positive non-small cell lung cancer in Japan. Jpn. J. Clin. Oncol. 2020, 50, 909-919. [CrossRef]

30. Ando, M.; Okamoto, I.; Yamamoto, N.; Takeda, K.; Tamura, K.; Seto, T.; Ariyoshi, Y.; Fukuoka, M. Predictive factors for interstitial lung disease, antitumor response, and survival in non-small-cell lung cancer patients treated with gefitinib. J. Clin. Oncol. 2006, 24, 2549-2556. [CrossRef]

31. Hotta, K.; Kiura, K.; Tabata, M.; Harita, S.; Gemba, K.; Yonei, T.; Bessho, A.; Maeda, T.; Moritaka, T.; Shibayama, T.; et al. Interstitial lung disease in Japanese patients with non-small cell lung cancer receiving gefitinib: An analysis of risk factors and treatment outcomes in Okayama Lung Cancer Study Group. Cancer J. 2005, 11, 417-424. [CrossRef] [PubMed]

32. Suzuki, H.; Aoshiba, K.; Yokohori, N.; Nagai, A. Epidermal growth factor receptor tyrosine kinase inhibition augments a murine model of pulmonary fibrosis. Cancer Res. 2003, 63, 5054-5059. [PubMed]

33. Ishii, Y.; Fujimoto, S.; Fukuda, T. Gefitinib prevents bleomycin-induced lung fibrosis in mice. Am. J. Respir. Crit. Care Med. 2006, 174, 550-556. [CrossRef] [PubMed]

34. Li, L.; Huang, W.; Li, K.; Zhang, K.; Lin, C.; Han, R.; Lu, C.; Wang, Y.; Chen, H.; Sun, F.; et al. Metformin attenuates gefitinibinduced exacerbation of pulmonary fibrosis by inhibition of TGF-beta signaling pathway. Oncotarget 2015, 6, 43605-43619. [CrossRef]

35. Del Barco, S.; Vazquez-Martin, A.; Cufi, S.; Oliveras-Ferraros, C.; Bosch-Barrera, J.; Joven, J.; Martin-Castillo, B.; Menendez, J.A. Metformin: Multi-faceted protection against cancer. Oncotarget 2011, 2, 896-917. [CrossRef]

36. Moodley, Y.P.; Misso, N.L.; Scaffidi, A.K.; Fogel-Petrovic, M.; McAnulty, R.J.; Laurent, G.J.; Thompson, P.J.; Knight, D.A. Inverse effects of interleukin-6 on apoptosis of fibroblasts from pulmonary fibrosis and normal lungs. Am. J. Respir. Cell Mol. Biol. 2003, 29, 490-498. [CrossRef]

37. Saito, F.; Tasaka, S.; Inoue, K.; Miyamoto, K.; Nakano, Y.; Ogawa, Y.; Yamada, W.; Shiraishi, Y.; Hasegawa, N.; Fujishima, S.; et al. Role of interleukin-6 in bleomycin-induced lung inflammatory changes in mice. Am. J. Respir. Cell Mol. Biol. 2008, 38, 566-571. [CrossRef]

38. Ishiguro, Y.; Ishiguro, H.; Miyamoto, H. Epidermal growth factor receptor tyrosine kinase inhibition up-regulates interleukin-6 in cancer cells and induces subsequent development of interstitial pneumonia. Oncotarget 2013, 4, 550-559. [CrossRef]

39. Wang, S.Z.; Rosenberger, C.L.; Bao, Y.X.; Stark, J.M.; Harrod, K.S. Clara cell secretory protein modulates lung inflammatory and immune responses to respiratory syncytial virus infection. J. Immunol. 2003, 171, 1051-1060. [CrossRef]

40. Mango, G.W.; Johnston, C.J.; Reynolds, S.D.; Finkelstein, J.N.; Plopper, C.G.; Stripp, B.R. Clara cell secretory protein deficiency increases oxidant stress response in conducting airways. Am. J. Physiol. 1998, 275, L348-L356. [CrossRef] 
41. Jones, K.G.; Holland, J.F.; Foureman, G.L.; Bend, J.R.; Fouts, J.R. Xenobiotic metabolism in Clara cells and alveolar type II cells isolated from lungs of rats treated with beta-naphthoflavone. J. Pharmacol. Exp. Ther. 1983, 225, 316-319. [PubMed]

42. Harada, C.; Kawaguchi, T.; Ogata-Suetsugu, S.; Yamada, M.; Hamada, N.; Maeyama, T.; Souzaki, R.; Tajiri, T.; Taguchi, T.; Kuwano, K.; et al. EGFR tyrosine kinase inhibition worsens acute lung injury in mice with repairing airway epithelium. Am. J. Respir. Crit. Care Med. 2011, 183, 743-751. [CrossRef] [PubMed]

43. Zwick, E.; Hackel, P.O.; Prenzel, N.; Ullrich, A. The EGF receptor as central transducer of heterologous signalling systems. Trends Pharmacol. Sci. 1999, 20, 408-412. [CrossRef]

44. Shim, J.J.; Dabbagh, K.; Ueki, I.F.; Dao-Pick, T.; Burgel, P.R.; Takeyama, K.; Tam, D.C.; Nadel, J.A. IL-13 induces mucin production by stimulating epidermal growth factor receptors and by activating neutrophils. Am. J. Physiol. Lung Cell. Mol. Physiol. 2001, 280, L134-L140. [CrossRef]

45. Cheng, C.Y.; Kuo, C.T.; Lin, C.C.; Hsieh, H.L.; Yang, C.M. IL-1beta induces expression of matrix metalloproteinase-9 and cell migration via a c-Src-dependent, growth factor receptor transactivation in A549 cells. Br. J. Pharmacol. 2010, 160, 1595-1610. [CrossRef]

46. Yamaoka, T.; Yan, F.; Cao, H.; Hobbs, S.S.; Dise, R.S.; Tong, W.; Polk, D.B. Transactivation of EGF receptor and ErbB2 protects intestinal epithelial cells from TNF-induced apoptosis. Proc. Natl. Acad. Sci. USA 2008, 105, 11772-11777. [CrossRef]

47. Edelblum, K.L.; Yan, F.; Yamaoka, T.; Polk, D.B. Regulation of apoptosis during homeostasis and disease in the intestinal epithelium. Inflamm. Bowel. Dis. 2006, 12, 413-424. [CrossRef]

48. Peschon, J.J.; Slack, J.L.; Reddy, P.; Stocking, K.L.; Sunnarborg, S.W.; Lee, D.C.; Russell, W.E.; Castner, B.J.; Johnson, R.S.; Fitzner, J.N.; et al. An essential role for ectodomain shedding in mammalian development. Science 1998, 282, 1281-1284. [CrossRef]

49. Yamaoka, T.; Arata, S.; Homma, M.; Homma, T.; Kusumoto, S.; Ando, K.; Manabe, R.; Kishino, Y.; Ohba, M.; Tsurutani, J.; et al. Blockade of EGFR Activation Promotes TNF-Induced Lung Epithelial Cell Apoptosis and Pulmonary Injury. Int. J. Mol. Sci. 2019, 20, 4021. [CrossRef]

50. Liu, J.Y.; Brass, D.M.; Hoyle, G.W.; Brody, A.R. TNF-alpha receptor knockout mice are protected from the fibroproliferative effects of inhaled asbestos fibers. Am. J. Pathol. 1998, 153, 1839-1847. [CrossRef]

51. Miyazaki, Y.; Araki, K.; Vesin, C.; Garcia, I.; Kapanci, Y.; Whitsett, J.A.; Piguet, P.F.; Vassalli, P. Expression of a tumor necrosis factor-alpha transgene in murine lung causes lymphocytic and fibrosing alveolitis. A mouse model of progressive pulmonary fibrosis. J. Clin. Investig. 1995, 96, 250-259. [CrossRef] [PubMed]

52. Ahn, M.J.; Sun, J.M.; Lee, S.H.; Ahn, J.S.; Park, K. Transient Asymptomatic Pulmonary Opacities during Osimertinib Treatment: "Stop or Go" Decision. J. Thorac. Oncol. 2016, 11, 2051-2052. [CrossRef] [PubMed]

53. Oshima, Y.; Tanimoto, T.; Yuji, K.; Tojo, A. EGFR-TKI-Associated Interstitial Pneumonitis in Nivolumab-Treated Patients with Non-Small Cell Lung Cancer. JAMA Oncol. 2018, 4, 1112-1115. [CrossRef] [PubMed]

54. Kubo, K.; Azuma, A.; Kanazawa, M.; Kameda, H.; Kusumoto, M.; Genma, A.; Saijo, Y.; Sakai, F.; Sugiyama, Y.; Tatsumi, K.; et al. Consensus statement for the diagnosis and treatment of drug-induced lung injuries. Respir. Investig. 2013, 51, 260-277. [CrossRef] [PubMed]

55. Min, J.H.; Lee, H.Y.; Lim, H.; Ahn, M.J.; Park, K.; Chung, M.P.; Lee, K.S. Drug-induced interstitial lung disease in tyrosine kinase inhibitor therapy for non-small cell lung cancer: A review on current insight. Cancer Chemother. Pharmacol. 2011, 68, 1099-1109. [CrossRef]

56. Stanam, A.; Gibson-Corley, K.N.; Love-Homan, L.; Ihejirika, N.; Simons, A.L. Interleukin-1 blockade overcomes erlotinib resistance in head and neck squamous cell carcinoma. Oncotarget 2016, 7, 76087-76100. [CrossRef]

57. Gelfo, V.; Rodia, M.T.; Pucci, M.; Dall'Ora, M.; Santi, S.; Solmi, R.; Roth, L.; Lindzen, M.; Bonafe, M.; Bertotti, A.; et al. A module of inflammatory cytokines defines resistance of colorectal cancer to EGFR inhibitors. Oncotarget 2016, 7, 72167-72183. [CrossRef] [PubMed]

58. Wang, X.; Xu, J.; Chen, J.; Jin, S.; Yao, J.; Yu, T.; Wang, W.; Guo, R. IL-22 Confers EGFR-TKI Resistance in NSCLC via the AKT and ERK Signaling Pathways. Front. Oncol. 2019, 9, 1167. [CrossRef]

59. Liu, Y.N.; Chang, T.H.; Tsai, M.F.; Wu, S.G.; Tsai, T.H.; Chen, H.Y.; Yu, S.L.; Yang, J.C.; Shih, J.Y. IL-8 confers resistance to EGFR inhibitors by inducing stem cell properties in lung cancer. Oncotarget 2015, 6, 10415-10431. [CrossRef]

60. Umekawa, K.; Kimura, T.; Kudoh, S.; Suzumura, T.; Oka, T.; Nagata, M.; Mitsuoka, S.; Matsuura, K.; Nakai, T.; Yoshimura, N.; et al. Plasma RANTES, IL-10, and IL-8 levels in non-small-cell lung cancer patients treated with EGFR-TKIs. BMC Res. Notes 2013, 6, 139. [CrossRef]

61. Ando, K.; Ohmori, T.; Inoue, F.; Kadofuku, T.; Hosaka, T.; Ishida, H.; Shirai, T.; Okuda, K.; Hirose, T.; Horichi, N.; et al. Enhancement of sensitivity to tumor necrosis factor alpha in non-small cell lung cancer cells with acquired resistance to gefitinib. Clin. Cancer Res. 2005, 11, 8872-8879. [CrossRef] [PubMed]

62. Gong, K.; Guo, G.; Gerber, D.E.; Gao, B.; Peyton, M.; Huang, C.; Minna, J.D.; Hatanpaa, K.J.; Kernstine, K.; Cai, L.; et al. TNF-driven adaptive response mediates resistance to EGFR inhibition in lung cancer. J. Clin. Investig. 2018, 128, 2500-2518. [CrossRef] [PubMed]

63. Pikarsky, E.; Porat, R.M.; Stein, I.; Abramovitch, R.; Amit, S.; Kasem, S.; Gutkovich-Pyest, E.; Urieli-Shoval, S.; Galun, E.; BenNeriah, Y. NF-kappaB functions as a tumour promoter in inflammation-associated cancer. Nature 2004, 431, 461-466. [CrossRef] [PubMed] 
64. Suh, C.H.; Park, H.S.; Kim, K.W.; Pyo, J.; Hatabu, H.; Nishino, M. Pneumonitis in advanced non-small-cell lung cancer patients treated with EGFR tyrosine kinase inhibitor: Meta-analysis of 153 cohorts with 15,713 patients: Meta-analysis of incidence and risk factors of EGFR-TKI pneumonitis in NSCLC. Lung Cancer 2018, 123, 60-69. [CrossRef]

65. Atagi, S.; Katakami, N.; Yoshioka, H.; Fukuoka, M.; Kudoh, S.; Ogiwara, A.; Imai, M.; Ueda, M.; Matsui, S. Nested case control study of proteomic biomarkers for interstitial lung disease in Japanese patients with non-small-cell lung cancer treated with erlotinib: A multicenter phase IV study (JO21661). Clin. Lung Cancer 2013, 14, 407-417. [CrossRef]

66. OECD Health Statistics. 2020. Available online: https://www.oecd.org/health/health-data.htm (accessed on 4 December 2020).

67. Raghu, G.; Remy-Jardin, M.; Myers, J.; Richeldi, L.; Wilson, K.C. The 2018 Diagnosis of Idiopathic Pulmonary Fibrosis Guidelines: Surgical Lung Biopsy for Radiological Pattern of Probable Usual Interstitial Pneumonia is Not Mandatory. Am. J. Respir. Crit. Care Med. 2019, 200, 1089-1092. [CrossRef]

68. Shi, L.; Tang, J.; Tong, L.; Liu, Z. Risk of interstitial lung disease with gefitinib and erlotinib in advanced non-small cell lung cancer: A systematic review and meta-analysis of clinical trials. Lung Cancer 2014, 83, 231-239. [CrossRef]

69. Hosomi, Y.; Morita, S.; Sugawara, S.; Kato, T.; Fukuhara, T.; Gemma, A.; Takahashi, K.; Fujita, Y.; Harada, T.; Minato, K.; et al. Gefitinib Alone Versus Gefitinib Plus Chemotherapy for Non-Small-Cell Lung Cancer with Mutated Epidermal Growth Factor Receptor: NEJ009 Study. J. Clin. Oncol. 2020, 38, 115-123. [CrossRef]

70. Noronha, V.; Patil, V.M.; Joshi, A.; Menon, N.; Chougule, A.; Mahajan, A.; Janu, A.; Purandare, N.; Kumar, R.; More, S.; et al. Gefitinib Versus Gefitinib Plus Pemetrexed and Carboplatin Chemotherapy in EGFR-Mutated Lung Cancer. J. Clin. Oncol. 2020, 38, 124-136. [CrossRef]

71. Saito, H.; Fukuhara, T.; Furuya, N.; Watanabe, K.; Sugawara, S.; Iwasawa, S.; Tsunezuka, Y.; Yamaguchi, O.; Okada, M.; Yoshimori, K.; et al. Erlotinib plus bevacizumab versus erlotinib alone in patients with EGFR-positive advanced non-squamous non-small-cell lung cancer (NEJ026): Interim analysis of an open-label, randomised, multicentre, phase 3 trial. Lancet Oncol. 2019, 20, 625-635. [CrossRef]

72. Herbst, R.S.; Ansari, R.; Bustin, F.; Flynn, P.; Hart, L.; Otterson, G.A.; Vlahovic, G.; Soh, C.H.; O'Connor, P.; Hainsworth, J. Efficacy of bevacizumab plus erlotinib versus erlotinib alone in advanced non-small-cell lung cancer after failure of standard first-line chemotherapy (BeTa): A double-blind, placebo-controlled, phase 3 trial. Lancet 2011, 377, 1846-1854. [CrossRef]

73. Seto, T.; Kato, T.; Nishio, M.; Goto, K.; Atagi, S.; Hosomi, Y.; Yamamoto, N.; Hida, T.; Maemondo, M.; Nakagawa, K.; et al. Erlotinib alone or with bevacizumab as first-line therapy in patients with advanced non-squamous non-small-cell lung cancer harbouring EGFR mutations (JO25567): An open-label, randomised, multicentre, phase 2 study. Lancet Oncol. 2014, 15, 1236-1244. [CrossRef]

74. Nakagawa, K.; Garon, E.B.; Seto, T.; Nishio, M.; Ponce Aix, S.; Paz-Ares, L.; Chiu, C.H.; Park, K.; Novello, S.; Nadal, E.; et al. Ramucirumab plus erlotinib in patients with untreated, EGFR-mutated, advanced non-small-cell lung cancer (RELAY): A randomised, double-blind, placebo-controlled, phase 3 trial. Lancet Oncol. 2019, 20, 1655-1669. [CrossRef]

75. Oxnard, G.R.; Yang, J.C.; Yu, H.; Kim, S.W.; Saka, H.; Horn, L.; Goto, K.; Ohe, Y.; Mann, H.; Thress, K.S.; et al. TATTON: A multi-arm, phase $\mathrm{Ib}$ trial of osimertinib combined with selumetinib, savolitinib, or durvalumab in EGFR-mutant lung cancer. Ann. Oncol. 2020, 31, 507-516. [CrossRef] [PubMed]

76. Müller, N.L.; White, D.A.; Jiang, H.; Gemma, A. Diagnosis and management of drug-associated interstitial lung disease. Br. J. Cancer 2004, 91 (Suppl. S2), S24-S30. [CrossRef]

77. Antoniou, K.M.; Margaritopoulos, G.A.; Tomassetti, S.; Bonella, F.; Costabel, U.; Poletti, V. Interstitial lung disease. Eur. Respir. Rev. 2014, 23, 40-54. [CrossRef]

78. Endo, M.; Johkoh, T.; Kimura, K.; Yamamoto, N. Imaging of gefitinib-related interstitial lung disease: Multi-institutional analysis by the West Japan Thoracic Oncology Group. Lung Cancer 2006, 52, 135-140. [CrossRef]

79. Chang, H.L.; Chen, Y.H.; Taiwan, H.C.; Yang, C.J. EGFR Tyrosine Kinase Inhibitor-Associated Interstitial Lung Disease during the Coronavirus Disease 2019 Pandemic. J. Thorac. Oncol. 2020, 15, e129-e131. [CrossRef]

80. Kohno, N.; Kyoizumi, S.; Awaya, Y.; Fukuhara, H.; Yamakido, M.; Akiyama, M. New serum indicator of interstitial pneumonitis activity. Sialylated carbohydrate antigen KL-6. Chest 1989, 96, 68-73. [CrossRef]

81. Kohno, N.; Hamada, H.; Fujioka, S.; Hiwada, K.; Yamakido, M.; Akiyama, M. Circulating antigen KL-6 and lactate dehydrogenase for monitoring irradiated patients with lung cancer. Chest 1992, 102, 117-122. [CrossRef]

82. Ohnishi, H.; Yokoyama, A.; Yasuhara, Y.; Watanabe, A.; Naka, T.; Hamada, H.; Abe, M.; Nishimura, K.; Higaki, J.; Ikezoe, J.; et al. Circulating KL-6 levels in patients with drug induced pneumonitis. Thorax 2003, 58, 872-875. [CrossRef] [PubMed]

83. Kawase, S.; Hattori, N.; Ishikawa, N.; Horimasu, Y.; Fujitaka, K.; Furonaka, O.; Isobe, T.; Miyoshi, S.; Hamada, H.; Yamane, T.; et al. Change in serum KL-6 level from baseline is useful for predicting life-threatening EGFR-TKIs induced interstitial lung disease. Respir. Res. 2011, 12, 97. [CrossRef] [PubMed]

84. Meyer, K.C.; Raghu, G.; Baughman, R.P.; Brown, K.K.; Costabel, U.; du Bois, R.M.; Drent, M.; Haslam, P.L.; Kim, D.S.; Nagai, S.; et al. An official American Thoracic Society clinical practice guideline: The clinical utility of bronchoalveolar lavage cellular analysis in interstitial lung disease. Am. J. Respir. Crit. Care Med. 2012, 185, 1004-1014. [CrossRef] [PubMed]

85. Tani, T.; Naoki, K.; Asakura, T.; Hirano, T.; Suzuki, S.; Masuzawa, K.; Hasegawa, H.; Kuroda, A.; Yasuda, H.; Ishii, M.; et al. Successful treatment of non-small-cell lung cancer with afatinib and a glucocorticoid following gefitinib- and erlotinib-induced interstitial lung disease: A case report. Mol. Clin. Oncol. 2016, 5, 488-490. [CrossRef] 
86. Kuo, L.C.; Lin, P.C.; Wang, K.F.; Yuan, M.K.; Chang, S.C. Successful treatment of gefitinib-induced acute interstitial pneumonitis with high-dose corticosteroid: A case report and literature review. Med. Oncol. 2011, 28, 79-82. [CrossRef]

87. Wong, C.K.; Lam, C.W.; Wu, A.K.; Ip, W.K.; Lee, N.L.; Chan, I.H.; Lit, L.C.; Hui, D.S.; Chan, M.H.; Chung, S.S.; et al. Plasma inflammatory cytokines and chemokines in severe acute respiratory syndrome. Clin. Exp. Immunol. 2004, 136, 95-103. [CrossRef]

88. González-Gay, M.A.; Loricera, J.; Blanco, R. Trial of Tocilizumab in Giant-Cell Arteritis. N. Engl. J. Med. 2017, 377, 1493. [CrossRef]

89. Toniati, P.; Piva, S.; Cattalini, M.; Garrafa, E.; Regola, F.; Castelli, F.; Franceschini, F.; Airò, P.; Bazzani, C.; Beindorf, E.A.; et al. Tocilizumab for the treatment of severe COVID-19 pneumonia with hyperinflammatory syndrome and acute respiratory failure: A single center study of 100 patients in Brescia, Italy. Autoimmun. Rev. 2020, 19, 102568. [CrossRef]

90. Michot, J.M.; Albiges, L.; Chaput, N.; Saada, V.; Pommeret, F.; Griscelli, F.; Balleyguier, C.; Besse, B.; Marabelle, A.; Netzer, F.; et al. Tocilizumab, an anti-IL-6 receptor antibody, to treat COVID-19-related respiratory failure: A case report. Ann. Oncol. 2020, 31, 961-964. [CrossRef]

91. Richeldi, L.; Cottin, V.; du Bois, R.M.; Selman, M.; Kimura, T.; Bailes, Z.; Schlenker-Herceg, R.; Stowasser, S.; Brown, K.K. Nintedanib in patients with idiopathic pulmonary fibrosis: Combined evidence from the TOMORROW and INPULSIS((R)) trials. Respir. Med. 2016, 113, 74-79. [CrossRef]

92. Kanayama, M.; Mori, M.; Matsumiya, H.; Taira, A.; Shinohara, S.; Kuwata, T.; Imanishi, N.; Yoneda, K.; Kuroda, K.; Tanaka, F. Perioperative pirfenidone treatment for lung cancer patients with idiopathic pulmonary fibrosis. Surg. Today 2020, 50, 469-474. [CrossRef] [PubMed]

93. Yamamoto, Y.; Yano, Y.; Kuge, T.; Okabe, F.; Ishijima, M.; Uenami, T.; Kanazu, M.; Akazawa, Y.; Yamaguchi, T.; Mori, M. Safety and effectiveness of pirfenidone combined with carboplatin-based chemotherapy in patients with idiopathic pulmonary fibrosis and non-small cell lung cancer: A retrospective cohort study. Thorac. Cancer 2020, 11, 3317-3325. [CrossRef] [PubMed]

94. Otsubo, K.; Kishimoto, J.; Kenmotsu, H.; Minegishi, Y.; Ichihara, E.; Shiraki, A.; Kato, T.; Atagi, S.; Horinouchi, H.; Ando, M.; et al. Treatment Rationale and Design for J-SONIC: A Randomized Study of Carboplatin Plus Nab-paclitaxel With or Without Nintedanib for Advanced Non-Small-cell Lung Cancer with Idiopathic Pulmonary Fibrosis. Clin. Lung Cancer 2018, 19, e5-e9. [CrossRef] [PubMed] 